\title{
CRITICAL POTENTIALS ASSOCIATED WITH EXCITA- TION OF ALKALI SPARK SPECTRA
}

\author{
Br F. L. Mohler
}

\section{ABSTRACT}

Various forms of electron tubes used in this work are described, including a new type of tube suitable for spectroscopic study of discharge with very low current density. Experimental results are as follows:

RUBIDICM.-Electrical measurements show critical potentials for production of radiation at 16.0 and 21.6 volts and with less certainty at 18.0, 25.2, and 68 volts. There is an increase in ionization at 16 volts. Spark lines are excited near 25 volts with small currents and at 16 volts with high-current density.

CAESIOM.-Spark lines are excited with small currents at 21.5 volts and with large currents near 14 volts. Another spectrum appears above 40 volts. A table of lines and intensities is given.

PotassiUm.--(Published results give radiation potentials at 19 and 23 volts.) There is an increase in ionization at 19 volts, and spark lines are excited at this point with high current and near 28 volts with low currents.

Soplum.-The spark lines appear near 35 and 44 volts, with large and small currents, respectively.

Litнium.- There is a critical radiation potential at 54 volts, and a spark line appears near this point.

Conclusions.- The potentials $\mathrm{Li} 54, \mathrm{Na} 35, \mathrm{~K} \mathrm{19}, \mathrm{Rb} 16$, Cs 14 measure the work required to remove a single electron from the rare gas shell of the normal atom. Each of these values is equal within experimental error to the ionization potential of the neighboring rare gas ion. The critical potential for low-current spark excitation gives the work required to remove two electrons by a single collision. The potentials $\mathrm{K} 23$ volts and $\mathrm{Rb} 21.6$ volts apparently measure the work required to remove the second electron from an ion with the valence electron removed.

\section{CONTENTS}

I. Introduction

II. Apparatus.

1. General procedure

III. Results

1. Rubidium

2. Caesium

3. Potassium

4. Sodium - - -

5. Lithium

6. Summary of results ....... 184

IV. Interpretation of results.

1. Normal levels......

2. Ionization potentials of ions.

3. Lithium

4. Miscellaneous results . . .

5. Conclusions 


\section{INTRODUCTION}

Several publications bearing on the subject of this paper have already appeared. ${ }^{1}$ Measurements of the photo-electric effect of the radiation from the thermionic discharge gave critical potentials near 35 volts in sodium and at 19 and 23 volts in potassium, while spectroscopic observations showed that near these potentials the spark spectra were excited. The structure of these spectra is of the rare gas arc type, and it follows that the excitation requires complete removal of the valence electron and displacement of an electron from the "rare gas shell" of the ion. It was assumed that this double excitation was accomplished by successive electron collisions, and that the observed potentials, 19 and 35 volts, measured the work required to remove an electron from the rare gas shell of the normal atom.

Some interesting problems arise in connection with these results. It has been questioned whether the critical radiation potentials above the first ionization point are in any case ionization potentials, and while the evidence seems to support the original interpretation the point at issue is of fundamental importance. ${ }^{2}$ As concerns the double excitation required for producing the ion spectrum, there are a variety of possible ways in which this may be accomplished by electron collisions, but there was little experimental evidence as to which are probable.

This paper describes a series of experiments carried out at intervals during the past three years to clear up some of these questions, and it includes experimental results on all of the alkalies. In the course of the research it became evident that it was important to control the current density in the discharge to distinguish between the effects of successive collisions and single impacts. However, when there is much ionization it becomes very difficult to estimate the current density at any point and unsafe to assume that it is proportional to the current. A well-known phenomenon of the thermionic discharge is that as the current or voltage is increased there may be a rather sudden transition from a uniform glow to a bundle of streamers. ${ }^{3}$ For this reason no attempt is made to draw quantitative conclusions concerning the probability of successive collisions, average life of ions, etc.

A recent publication by Dejardin ${ }^{4}$ summarizes similar experiments with the rare gases, and some interesting relations between critical potentials of the alkalies and of the rare gases are found. The

1 Soft X Rays from Gases, Mohler and Foote, Bureau of Standards Sci. Paper No. 425; 1922 . Enhanced Spectra of Sodium and Potassium in the Low Voltage Arc, Foote, Meggers, and Mohler, Astro. Phys. J., 55, pp. 145-161; 1922. Further references to brief notes on other alkalies are given later.

2 See "Interpretation of Critical Potentials," Mohler, Bul. N. R. C., 9, pp. 98-110; 1924.

${ }^{3}$ The theory of streamer formation is discussed by Johnson, J. O. S. A. and R. S. I., 6, p. 701; 1922.

" EIcitation of spectra of monatomic gases," Annales de Phys., 11, pp. 241-327; 1924. 
general conclusions as to the conditions for exciting spark lines are consistent with our results.

There are several recent developments which have an important bearing on the technique of critical potential measurements. It is now known that when the current in a thermionic discharge is rather large oscillations may occur, and with the usual type of circuits the peak voltage of such oscillations may far exceed the reading of a direct-current voltmeter across the tube. ${ }^{5}$ The possibility of error is eliminated if there is no external resistance in the discharge circuit. Another source of uncertainty arises from the fact that it is possible to have a concentration of positive ions sufficient to raise the potential of the space appreciably above that of the electrodes. Langmuir and Jones ${ }^{6}$ have measured the potential of this space charge and have found that in extreme cases it may amount to many volts. As the amount depends on the applied voltage as well as the current and gas pressure, the usual methods of correction become unreliable where it is specifically desired to use large currents.

A serious limitation on the work with alkali metals arises from the thermionic emission from all electrodes in the presence of the alkali vapor. ${ }^{7}$ In caesium vapor the emission is so great that sensitive electrical measurements are impossible. This phenomenon has, however, been used to advantage in a new type of discharge tube suitable for the spectroscopic study of excitation with very lowcurrent density.

\section{APPARATUS}

Most of the methods used have been described elsewhere, ${ }^{8}$ and we will give only a brief description of the type of electron tubes employed.

Tube 1 used for measurement of ionization and of the photoelectric effect of radiation is illustrated diagrammatically in Figure 1. Electrodes $B, C$, and $D$ were cylinders of platinum, the dotted portions being of fine gauze, and the cathode $A$ was an oxide coated platinum strip. The containing tube was pyrex with tungstenpyrex seals. This was heated in an electric furnace with the metal studied in a cooler side tube as in the set-up shown in Figure 3. In experiments with rubidium the body of the tube was maintained at about $200^{\circ} \mathrm{C}$. The electrical connections shown in Figure 1 are for the measurement of the photo-electric effect of radiation. For every setting of the voltage $V$ across the discharge both the discharge

\footnotetext{
B Bär, Laue, and Mejer, Zeits. f. Phys., 20, pp. 166-168; 1924. Eckart and Compton, Phys. Rev., 24, pp. $97-112 ; 1924$.

" "Quantitative studies of ionization," Sci., 59, pp. 380-382; 1924.

${ }^{7}$ A theory of these effects is given by Langmuir and Kingdon, Sci., 57, p. 58; 1923.

8 "Critical potential methods," K. T. Compton, Bul. N. R. C., 0, pp. 1-60; 1924.
} 
current and the photo-electric current are measured and the ratio of photo-electric effect to discharge current is plotted against the applied potential. Ionization can be measured by putting both $O$ and $D$ at the potential $-V$, and measuring the current to them. (Only a small fraction of this current arises from photo-electric effect.)

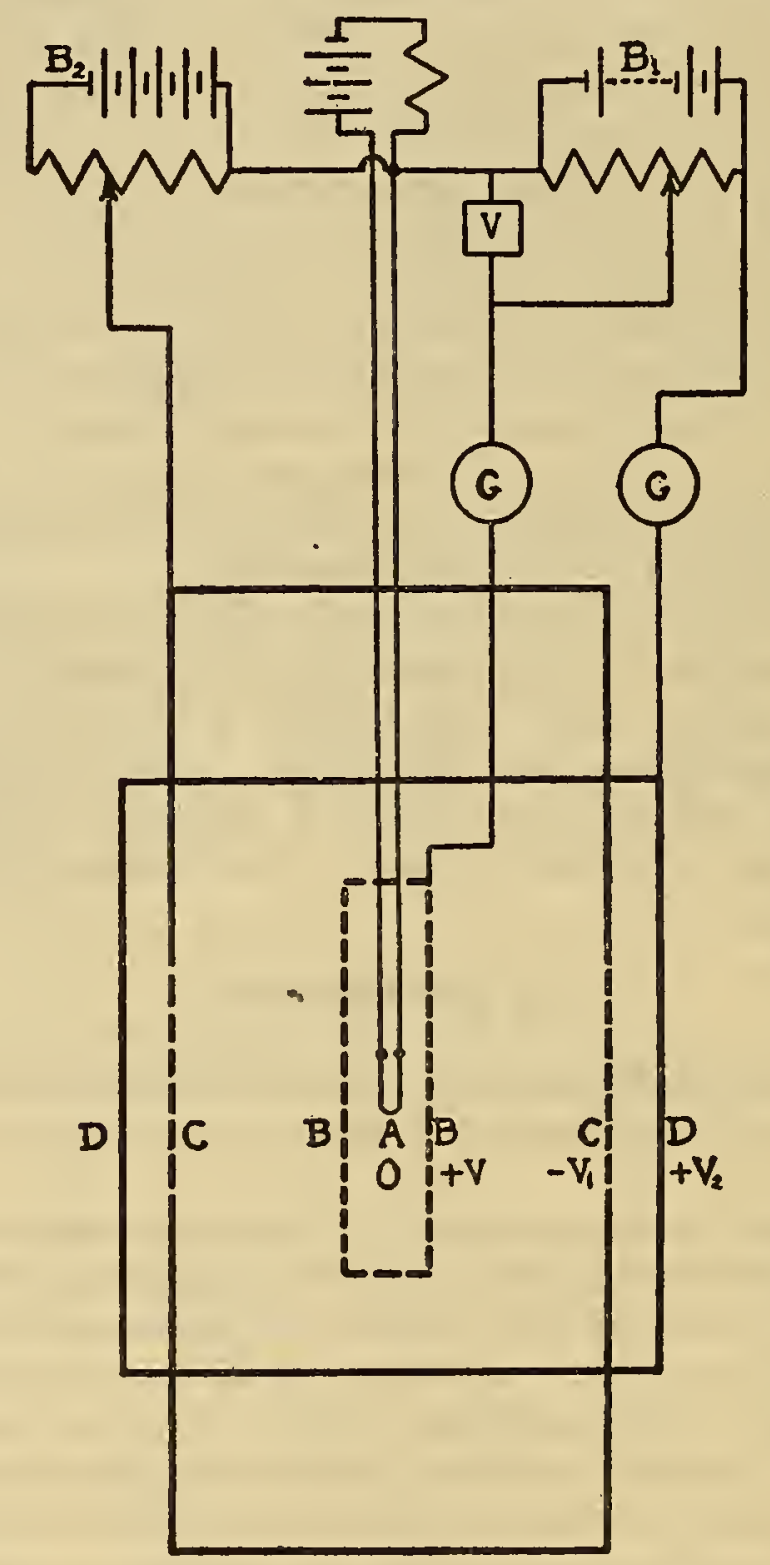

Fig. 1.-Electrodes and electrical connections for measuring photo-electric effect of radiation from a thermionic discharge

Tube 2 (fig. 2 ) is similar to tube 1 in principle, and a corresponding lettering is used. The electrodes were contained in a pyrex tube with brass end plates, and potentials were applied as in tube 1 , while the metal cylinder $E$ was maintained either at $+V$ or $-V_{1}$. This tube was used with lithium, and the metal was placed near the middle of the tube and heated to about $550^{\circ} \mathrm{C}$. 
Tube 3 was a three-electrode tube used for measuring positive ion currents in potassium vapor. It is represented diagrammatically by Figure 1 , with the electrode $C$ omitted and $D$ at the potential $-V_{1}$. The potassium was in the body of the tube, which was heated to about $180^{\circ} \mathrm{C}$.

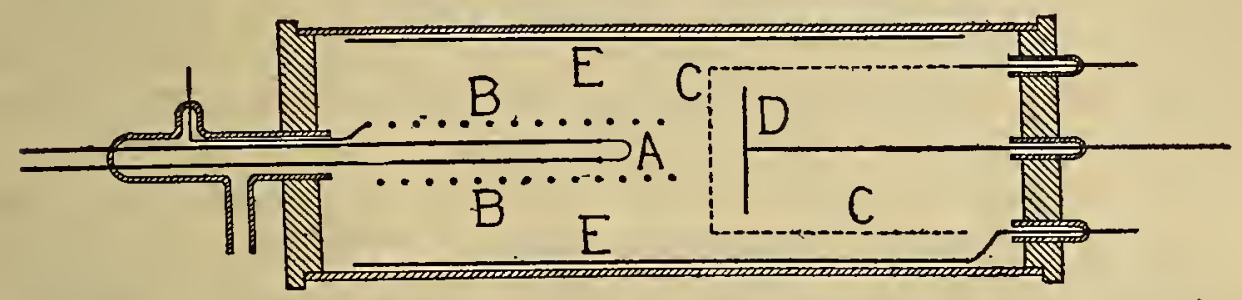

FIG. 2.-Diagram of tube used for measuring radiation potentials of lithium

The lettering corresponds to Figure 1. The metal cylinder $E$ was either at $+V$ or $-V_{1}$ volts.

Tube 4 (fig. 3) was designed for spectroscopic observations. The cathode was an oxide coated platinum strip about $0.5 \mathrm{~cm}$ wide and $4 \mathrm{~cm}$ long. Both the grid surrounding the cathode and the metal sheath inside the containing tube were at a potential $+V$ with respect to the cathode. The containing tube of pyrex had a flat end plate fused to it, and the entire tube was heated in an electric furnace which was noninductively wound. In experiments with rubidium the metal was at a temperature of about $150^{\circ} \mathrm{C}$.

Tube 4a: The spectra of sodium and potassium discharges were studied in a tube similar to (4), except that a window of quartz glass was sealed with wax to a tube projecting about $40 \mathrm{~cm}$ beyond the furnace. The metal was placed in the hottest part of the tube at a temperature of about $260^{\circ} \mathrm{C}$. for sodium and $140^{\circ} \mathrm{C}$. for potassium.

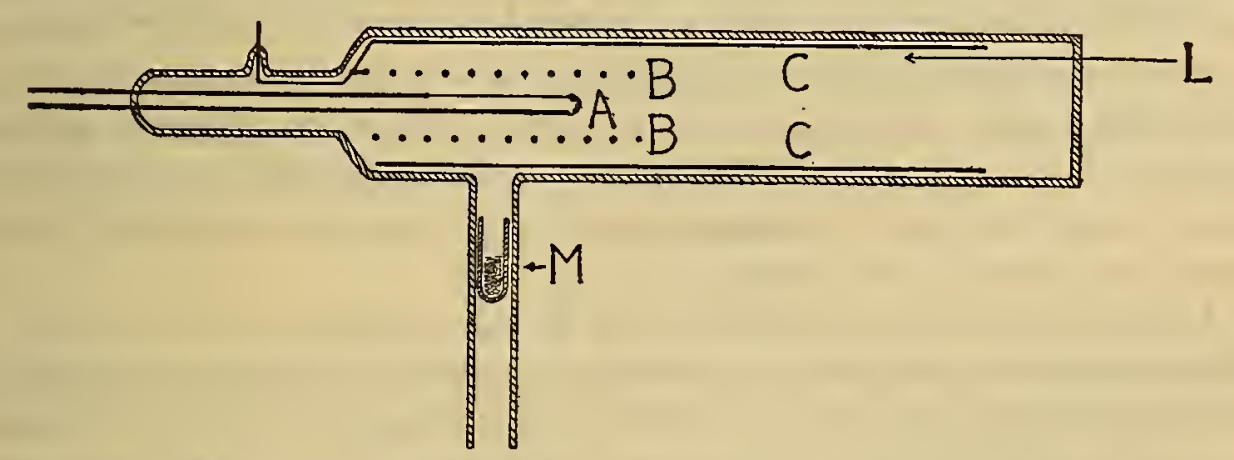

Fra. 3.-Tube for spectroscopic study of the thermionic discharge

The cathode $A$ was at zero potential and the grid $B$ and cylinder $C$ at $+V . \quad L$ is the line of sight and $\boldsymbol{M}$ the alkali metal which was being studied

Tube 5: Preliminary observations of rubidium and caesium spectra were made in a tube nearly identical with (4), except that it was heated by a helix of copper wire. This gave a magnetic field of about 200 ampere turns parallel to the axis of the tube, so that the discharge formed a narrow beam (about $1 \mathrm{~cm}$ in diameter) along the axis and the line of sight. This arrangement gives the greatest possi- 
ble illumination of the spectroscope slit in proportion to the radiation produced, but the concentration increases the current density.

Tube 5a, used for lithium vapor, resembled tube 5 in principle, but the radiation was viewed from the opposite end. The magnetic field and discharge beam made a slight angle with the line of sight, so that it was possible to avoid looking directly at the incandescent cathode. The tube was rertical with the lithium contained in the bottom at a temperature between 550 and $600^{\circ} \mathrm{C}$. The quartz window was about $40 \mathrm{~cm}$ above the heater.

Tube 6: Figure 4 shows a tube which was designed to give a discharge of extremely low-current density. The large thermionic emission from metals exposed to alkali vapors makes it feasible to use a large surface as cathode. In this set-up, reversing the usual procedure, we made the outer metal sheath negative, while wires running the length of the tube near the axis served as the anode. The containing tube had a quartz window with a quartz-pyrex Cooper Hewitt seal joining it to the rest of the tube. With a non-

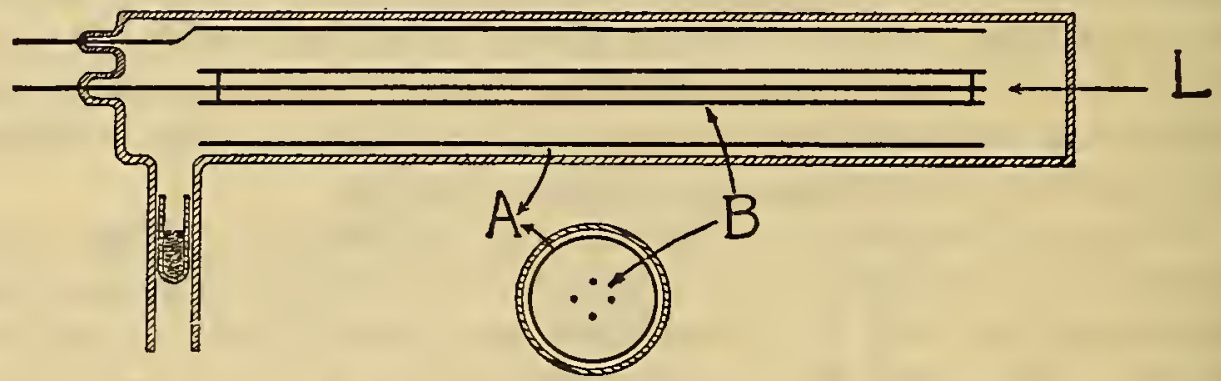

Frg. 4.-End and side views of tube used for spectroscopic study of low-current discharge

The metal cylinder $A$ served as cathode and the wires $B$ were the anode. $L$ is the line of sight

inductive electric heater the discharge is a fairly uniform glow, but brightest along the axis, so that very efficient illumination of the spectroscope is possible. Excessive vapor pressure or a relatively small magnetic field (5-ampere turns) will draw the discharge away from the center of the tube.

In experiments with caesium the metal was kept at $100^{\circ} \mathrm{C}$. by a steam bath and the body of the tube superheated until a current of 10 or 20 milliamperes was obtained. This was about $400^{\circ} \mathrm{C}$., but the current depended on the previous treatment of the tube, and some patience was required to secure a steady condition. The same tube was used with rubidium and a sufficient current obtained with the metal at $200^{\circ} \mathrm{C}$. and the tube at $550^{\circ} \mathrm{C}$., but the quartz became discolored under these conditions, and the quartz-pyrex graded seal broke when the tube cooled.

Tube 6a: The same method was employed for potassium vapor, using a vertical tube with a window at the top which was kept cool. The potassium was placed in the bottom of the tube, which was at 
about $250^{\circ} \mathrm{C}$., while the electrodes were at $500^{\circ} \mathrm{C}$. As the potassium condensed above the electrodes and flowed down over them the vapor pressure was high and unsteady.

\section{GENERAL PROCEDURE}

In the more recent experiments we have avoided error in voltage measurements arising from oscillations in the discharge by using a battery giving at most only a few volts more than the applied potential. This precaution is particularly desirable with large currents ( 0.2 to 0.5 ampere), but the control of such currents without series resistance is troublesome. For protection of the apparatus the discharge circuit was fused, and for this purpose small flashlight lamps were convenient.

In the type of tubes used for electrical measurements of radiation the current density is an unknown factor. The inner grid ( $B$ of fig. 1) was of fine gauze, so that the current was very much larger inside than outside, and the radiation came from both sides. Currents were of the order of 1 to 10 milliamperes.

In the spectroscopic work (excepting a few visual observations) a Hilger type $C$ quartz spectrograph and unstained photographic plates were used. In securing a series of photographs it was desired to obtain equal intensities of arc lines, so as to detect relative changes in intensity of spark lines. This condition is approximated over a small voltage range by keeping the product of time of exposure times discharge current constant.

Commercial metallic sodium, potassium, and lithium were used in these experiments. Rubidium and caesium were made by heating commercial cp chlorides with calcium chips in vacuo. Each of the metals contained a trace of the others, and the neighboring alkalies to the one studied were, in general, the most prominent impurities. Liquid air traps excluded mercury, and gas pressures were kept down to a few ten-thousandths of a millimeter or less.

\section{RESULTS}

\section{RUBIDIUM}

Figure 5 shows the results of electrical measurements in rubidium vapor using tube 1 (fig. 1). Curves $I, I I$, and $I V$ give the photoelectric effect of radiation as a function of the voltage applied to excite the discharge. Curve $I I$ is the mean of eight curves measured under similar conditions, while curve $I V$ gives a single set of readings extending to the lowest voltage at which radiation was measurable (the first ionization potential). These curves show clearly two critical potentials at 16.0 and 21.6 volts. Curve $I$ shows the mean of a number of curves taken under different conditions, presumably lower vapur pressure. This set of data gives some evidence (admittedly questionable) of a critical potential at $34001^{\circ}-25-2$ 
25.2 volts as well as one at 21.6 and possibly a third point, not shown on Figure 5, at 18 volts. Spectroscopic evidence supports the reality of the 25.2-volt point.

Curve $I I I$ is the mean of three ionization curves taken under the same conditions as the radiation curve $I I$. The positive ion current begins near 4 volts, and as the theoretical value of the ionization potential is 4.16 volts we assume that the initial potential correction is nearly zero. There is a small increase in ionization near 16 volts. Curve $V$ gives a part of curve $I I I$ on a much larger scale, and it is thus emphasized that this increase is much larger than the accidental irregularities. Curves not shown gave evidence of another radiation potential near 68 volts.

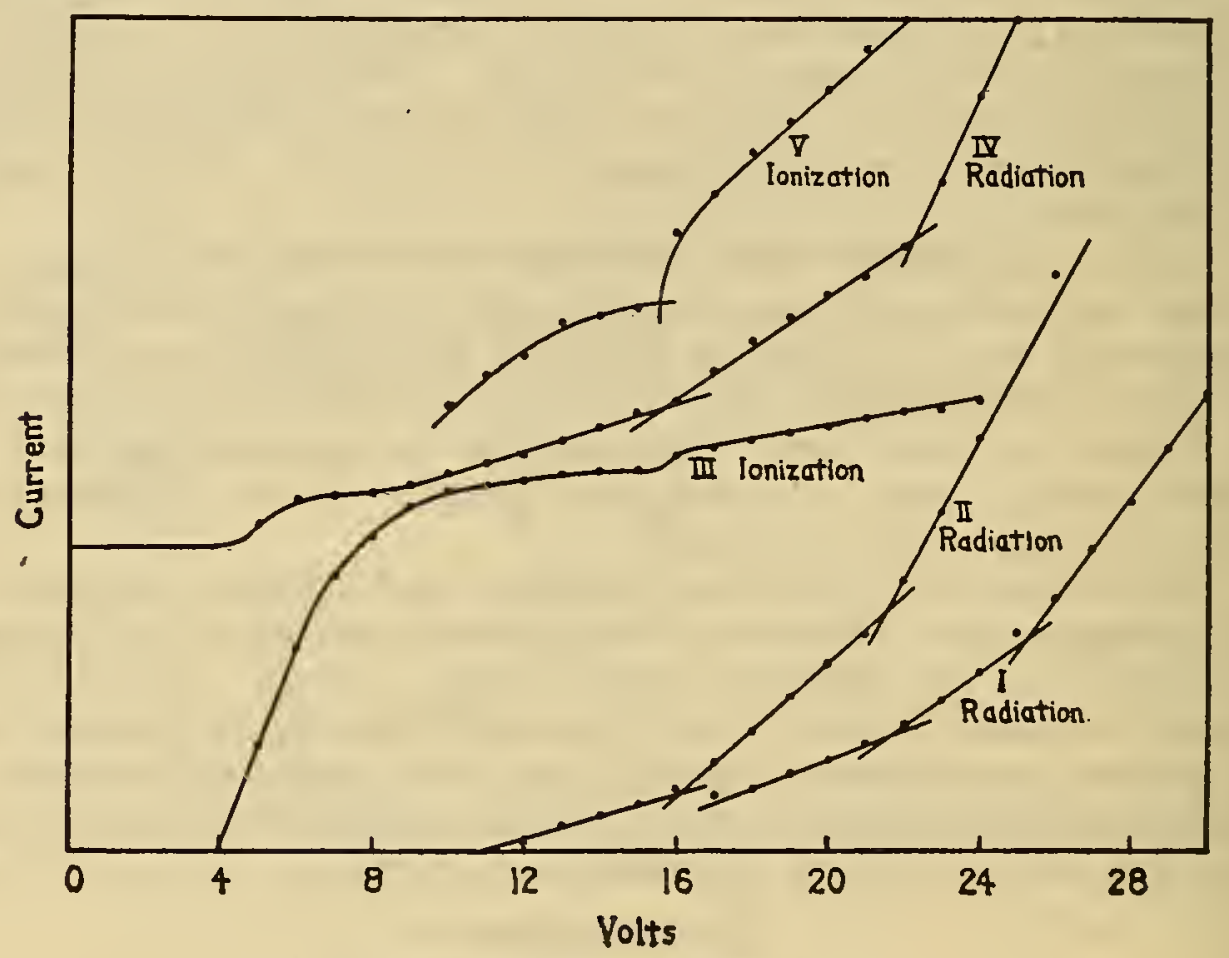

Fig. 5.-Electrical measurements in rubidium vapor

Ordinates are currents per unit discharge current

Some spectroscopic results on excitation of rubidium and caesium have already been presented. ${ }^{9}$ In this preliminary work, tube 5 was used with a magnetically concentrated discharge of 0.1 to 0.5 ampere. The spark lines of rubidium began to appear at 14 volts, though in one instance one or two lines were visible at a very much lower voltage. The latter effect could not be repeated, and we assume that oscillations in the discharge explain the observation. The relatively high current densities make the space charge effect large and the estimate of the actual minimum voltage uncertain and probably low.

- Mohler, Foote, Ruark and Kiess, J. O.S. A. and R. S. I. 7, p. 62; 1923. Abstract of paper read before Optical Society, October, 1922. 
The experiments were continued with tubes 4 and 6 with particular attention to the effect of current density. In tube 4 the current spread out from a cathode of area $2 \mathrm{~cm}^{2}$, while in tube 6 the current converged from an area of $100 \mathrm{~cm}^{2}$. Probably, for equal currents the density was at least ten times as great in tube 4 as in tube 6 along the line of sight. Table 1 summarizes the results. All potentials are adjusted by the rather unsatisfactory method of assuming that the difference between the applied potential at which the arc strikes and the ionization potential gives the initial velocity correction. The results show that the presence of spark lines between 17 and 25 volts depends on the current density, and that with currents of about 0.07 ampere spark lines are absent at 15.5 volts, remain very faint between 17 and 21.5 volts, but increase rapidly between 21.5 and 23.5. For currents larger than 0.09 ampere (as in the preliminary research) there is a lower minimum voltage, but this is probably accounted for by the unmeasured space charge effect. A rough estimate of the current density required to produce spark lines at 20 volts is 0.01 to 0.02 ampere per square centimeter.

TABLE 1.-Summary of spectroscopic results with rubidium

\begin{tabular}{|c|c|c|c|}
\hline Reference No. & Volts & $\begin{array}{l}\text { Current } \\
\text { amperes }\end{array}$ & Intensity of spark lines \\
\hline 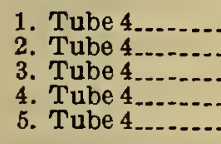 & $\begin{array}{l}20 \\
20 \\
20 \\
15.5 \\
17\end{array}$ & $\begin{array}{l}0.005 \\
.06 \\
.35 \\
.09 \\
.08\end{array}$ & $\begin{array}{l}\text { No trace. } \\
\text { Strongest lines visible. } \\
\text { Many lines visible; strongest comparable with arc lines } 1 s-3 p_{1}, \text {. } \\
\text { No trace. } \\
\text { Intensity as in (2). }\end{array}$ \\
\hline $\begin{array}{l}\text { 6. Tube } 4 \\
\text { 7. Tube } 4 \\
\text { 8. Tube } 4 \\
\text { 9. Tube } 4 \\
\text { 10. Tube } 4\end{array}$ & $\begin{array}{l}20.5 \\
21.5 \\
23.5 \\
24.5 \\
32\end{array}$ & $\begin{array}{l}.06 \\
.07 \\
.07 \\
.07 \\
.06\end{array}$ & $\begin{array}{l}\text { Strongest lines comparable with arc } 18-4 p_{1,2 .} \\
\text { Do. } \\
\text { Much stronger, similar to (3). } \\
\text { Much stronger than (8). } \\
\text { Very strong. }\end{array}$ \\
\hline $\begin{array}{l}\text { 11. Tube } 4 \\
\text { 12. Tube } 6 \\
\text { 13. Tube } 6 \\
\text { 14. Tube } 6\end{array}$ & $\begin{array}{l}32 \\
25 \\
26 \\
28\end{array}$ & $\begin{array}{l}.6 \\
.01 \\
.01 \\
.01\end{array}$ & $\begin{array}{l}\text { Almost identical with (10). } \\
\text { Visual observations give first trace of spark lines at this voltage. } \\
\text { Spark lines comparable with (8) and (3). } \\
\text { Spark lines comparable with (9). }\end{array}$ \\
\hline
\end{tabular}

The spark spectrum of rubidium has been measured with precision (wave lengths given to $0.001 \mathrm{~A}$ ) by Reinheimmer. ${ }^{10}$ One hundred and thirty lines are classified in multiplets of the rare gas arc types found by Paschen in neon. Reinheimmer used as a source a vacuum tube containing helium and rubidium excited by an induction coil with a spark gap in series and condenser in parallel. Dunoyer ${ }^{11}$ has measured the rubidium spectrum excited in the induction-ring discharge and gives wave lengths of 230 spark lines between 5500 and $2200 \mathrm{~A}$ with a precision of a few tenths of an Ängstrom.

Spectra of the thermionic discharge at 32 volts showed nearly all the spark lines listed by Reinheimmer between 5100 and $3200 \mathrm{~A}$ in so far as they could be resolved by our instrument. Our estimates 
of the relative intensities of different spark lines agree with his, but the intensity of spark as compared with arc lines is very much less in the thermionic discharge. The spark lines which appear at the lowest voltages are the strongest lines of this spectrum. We find no evidence that different lines have different excitation potentials. The intensities given by Dunoyer for lines excited by the induction discharge differ markedly from the estimates given by Reinheimmer and by the author.

\section{CAESIUM}

Electrical measurements of radiation were not practicable because of the thermionic emission from all the electrodes. A preliminary note on the excitation of the spark spectrum of caesium is referred to in the preceding section. The remarks on the work with rubidium apply in toto to the results with caesium. Spark lines appeared near 14 volts, but the correction to be applied is uncertain, and evidence that one line at $4364 \mathrm{~A}$ was excited at a muchlower voltage is probably unreliable.

Further work with caesium was limited to a study of the excitation under conditions of low-current density. Tube 6 was used with currents between 0.01 and 0.05 ampere. The initial potential correction estimated from the applied voltage required to excite the mercury arc lines is about 2 volts. The results, giving corrected voltages, are as follows: Spark lines are faintly visible at 20 volts and of about the same intensity at 21 volts. Exposures at 22, 23, 24,25 , and 28 volts show a rapid increase in relative intensity of spark as compared with arc lines. Between 28 and 32 volts the change is not appreciable, but between 32 and 40 and between 40 and 80 there is a noticeable enhancement of all spark lines. In the latter interval a new spectrum appears. We conclude that the first spark spectrum is excited near 21.5 volts with small currents, and roughly 8 volts lower with high currents.

The spectrum of caesium excited by a high voltage discharge through a mixture of helium and caesium has been measured by Sommer. ${ }^{12}$ He gives wave lengths to 0.01 or $0.001 \mathrm{~A}^{*}$ of 361 spark lines in the range between 7300 and $3200 \mathrm{~A}$. Fifty-one of these lines are arranged in two complicated multiplets of rare gas type and 44 other lines have frequency differences which apparently relate them to the same spectrum. Dunoyer ${ }^{13}$ has studied the induction discharge in caesium and gives wave lengths of 330 lines in the range of the quartz spectrograph.

In Table 2 we give lines listed by Sommer between 5400 and 3200 as having an intensity one or more (fainter lines did not, in general, appear on our plates). With these are given intensities as estimated by Sommer, by Dunoyer, and by the author for five different voltages.

12 "On the Spark Spectrum of Cs." Ann. der Phys., 75, pp. 163-181; 1924.

13 J. de Phys. loc. cit. 
TABLE 2.-Caesium spark spectrum

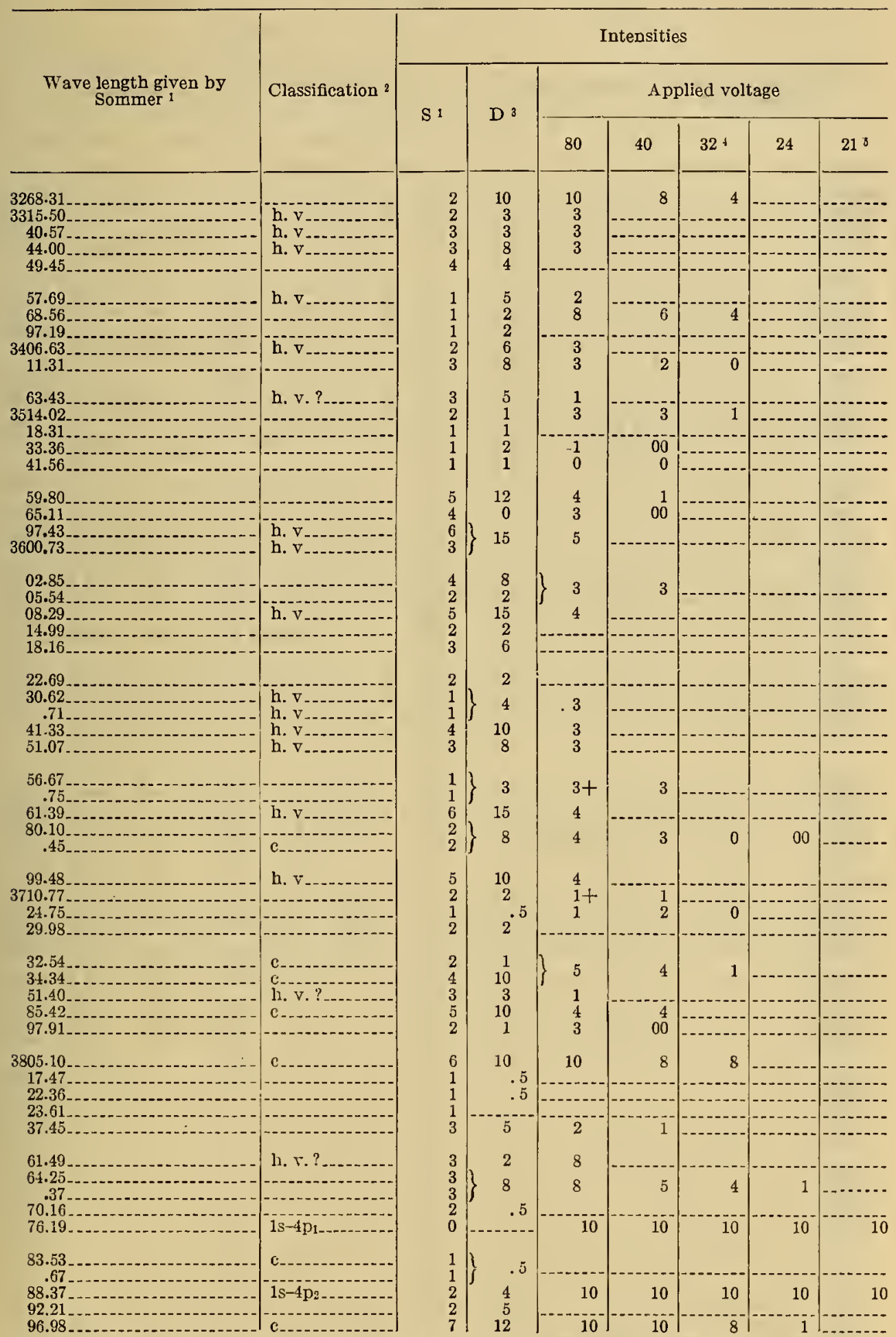

1 Wave lengths taken from Sommer. (Ann. der Phys., 75, pp. 165-168, 1924.) He gives spectra to 7300A and includes many fainter lines listed as zero intensity. "Wave lengths are generally given to one more significant figure. Under $\mathrm{S}$ we give intensity estimates of Sommer.

$2 \mathrm{~h}$. $\nabla$. indicates lines not excited at 40 volts but present at 80 ; c, lines classified by Sommer in rare gas type roultiplets and lines showing similar frequency differences. (See his paper Tables $6 \mathrm{a}, 6 \mathrm{~b}$, and 7 .)

D, intensity estimates of Dunoyer (J. de Phys., 3, pp. 272-278; 1922.)

1 Practically identical intensity at 28 volts.

- Nearly the same intensity at 20 and 22 volts. 
TABLE 2.-Caesium spark spectrum-Continued

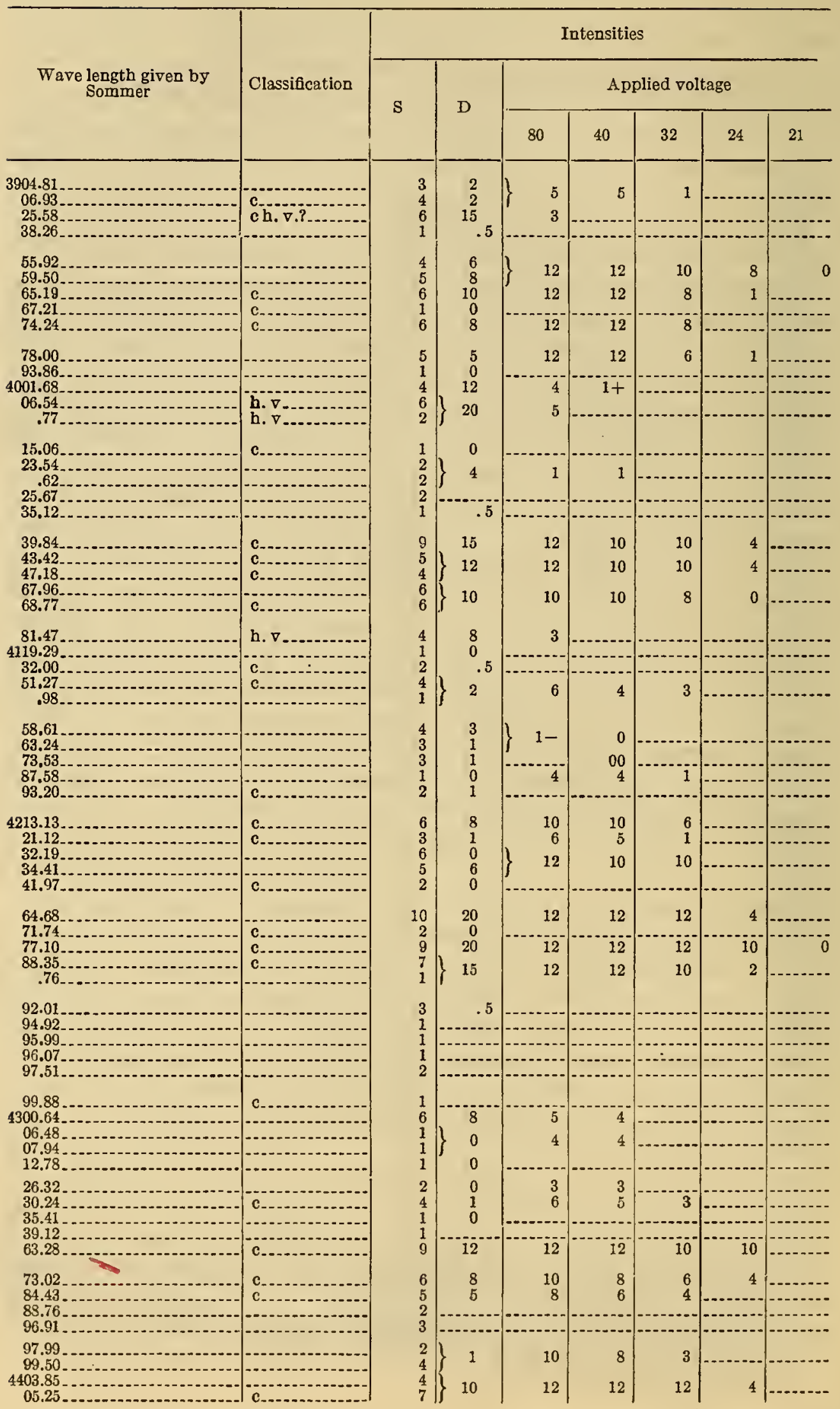


TABLE 2.-Caesium spark spectrum-Continued

\begin{tabular}{|c|c|c|c|c|c|c|c|c|}
\hline \multirow{3}{*}{$\begin{array}{l}\text { Wave length given by } \\
\text { Sommer }\end{array}$} & \multirow{3}{*}{ Classification } & \multicolumn{7}{|c|}{ Intensities } \\
\hline & & \multirow{2}{*}{$\mathrm{s}$} & \multirow{2}{*}{ D } & \multicolumn{5}{|c|}{ Applied voltage } \\
\hline & & & & 80 & 40 & 32 & 24 & 21 \\
\hline \multicolumn{9}{|l|}{$\begin{array}{l}4410.21-- \\
11.12-\end{array}$} \\
\hline 25.06 & & $\begin{array}{l}2 \\
4\end{array}$ & 10 & 4 & 2 & & & \\
\hline $\begin{array}{l}35.71 \\
44.00 \\
47.65\end{array}$ & & $\begin{array}{l}4 \\
2 \\
2\end{array}$ & 4.5 & $\begin{array}{r}10 \\
6\end{array}$ & $\begin{array}{r}10 \\
4\end{array}$ & $\stackrel{6}{1}$ & & \\
\hline $\begin{array}{l}50.7 \\
67.6\end{array}$ & & $\begin{array}{l}1 \\
3\end{array}$ & .5 & $\overline{6}$ & 4 & i & 0 & \\
\hline \multirow{2}{*}{\multicolumn{9}{|c|}{$\begin{array}{l}69.98 \\
93.66 \\
96.76\end{array}$}} \\
\hline & & & & & & & & \\
\hline & & $\begin{array}{l}1 \\
1\end{array}$ & 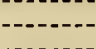 & & & & & \\
\hline \multicolumn{9}{|l|}{4501.53} \\
\hline \multirow{2}{*}{\multicolumn{9}{|c|}{$\begin{array}{l}0631 \\
.85\end{array}$}} \\
\hline \multirow{2}{*}{\multicolumn{9}{|c|}{ ce- }} \\
\hline & & & & & & & & \\
\hline \multirow{3}{*}{$\begin{array}{l}32.50-\ldots \\
38.94 \\
55.36 \\
72.61 \\
93.18\end{array}$} & c & 2 & $-\cdots$ & & & & & \\
\hline & ls $-3 p_{1 . .}$ & $\begin{array}{r}0 \\
4 \\
\end{array}$ & 1 & $\frac{11}{12}$ & $\begin{array}{ll}11 \\
12\end{array}$ & $\begin{array}{r}8 \\
12\end{array}$ & $12 \overline{2}$ & 12 \\
\hline & $1 s-3 p_{2-}$ & $\frac{2}{3}$ & $0^{.5}$ & 12 & 12 & 12 & 12 & \\
\hline \multirow{2}{*}{\multicolumn{9}{|c|}{$\begin{array}{r}4603.76-10 \\
10.51 \\
12.18\end{array}$}} \\
\hline & & & & & & & & \\
\hline \multicolumn{9}{|c|}{16.013} \\
\hline & & 3 & 10 & 12 & 12 & 10 & & \\
\hline \multicolumn{9}{|l|}{$20.59-$} \\
\hline \multicolumn{9}{|l|}{$\begin{array}{l}23.09 \\
28.34\end{array}$} \\
\hline \multicolumn{9}{|c|}{ 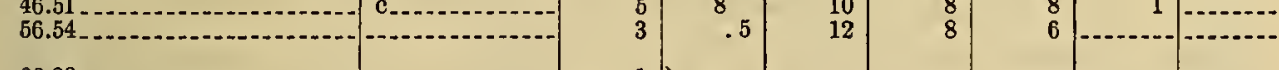 } \\
\hline \multirow{2}{*}{\multicolumn{9}{|c|}{$\begin{array}{l}66.89 \\
70.28\end{array}$}} \\
\hline \multirow{2}{*}{\multicolumn{9}{|c|}{$\begin{array}{r}95.61 \\
4732.98 \\
63.62 \\
-10-1-\end{array}$}} \\
\hline & & $\begin{array}{l}4 \\
5\end{array}$ & $\begin{array}{r}5 \\
12\end{array}$ & $\begin{array}{l}12 \\
12\end{array}$ & $\begin{array}{l}12 \\
12\end{array}$ & & & \\
\hline \multirow{2}{*}{\multicolumn{9}{|c|}{$\begin{array}{r}86.36 \\
4830.16 \\
51.58 \\
70.02\end{array}$}} \\
\hline & & 6 & 12 & 12 & 10 & 10 & 10 & 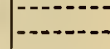 \\
\hline \multicolumn{9}{|l|}{70.02} \\
\hline \multicolumn{9}{|l|}{$\begin{array}{l}79.83-1 . .1 \\
80.19\end{array}$} \\
\hline \multicolumn{9}{|l|}{$4952.84-\cdots$} \\
\hline $\begin{array}{l}72.59-- \\
81.65_{-}\end{array}$ & c.... & $\begin{array}{l}5 \\
1\end{array}$ & 4 & 12 & 10 & 10 & 2 & \\
\hline 5001.64 & & 1 & $\ldots$ & 3 & 1 & & & \\
\hline & & & & & 0 & & & \\
\hline & & $\begin{array}{l}1 \\
6\end{array}$ & 5 & 12 & 10 & 8 & 3 & \\
\hline $\begin{array}{l}52.70 \\
59.87\end{array}$ & & 3 & 0 & 12 & 8 & 3 & & \\
\hline & & $\begin{array}{l}3 \\
1\end{array}$ & $\frac{1}{1}$ & & 6 & & & \\
\hline & & $\begin{array}{r}2 \\
4 \\
\end{array}$ & 5 & 7 & $\begin{array}{l}5 \\
3\end{array}$ & 3 & & \\
\hline 5169.41 & & 1 & & & & & & \\
\hline 6209.44 & & 2 & $?$ & 6 & ? & 1 & & \\
\hline & & 1 & 2 & & & & & \\
\hline $\begin{array}{l}27.0 \\
49.3\end{array}$ & c--.-......... & 8 & 8 & 8 & 6 & $\begin{array}{r}5 \\
2\end{array}$ & 4 & \\
\hline 74.04 & c................ & $\begin{array}{c}0 \\
4\end{array}$ & 2 & $\begin{array}{l}0 \\
3\end{array}$ & 1 & & & \\
\hline
\end{tabular}


The spectra observed by the author as well as by Dunoyer extend much farther into the ultra-violet, but for the sake of brevity we limit the table to the range of precision measurements. In the ultra-violet, as in the range tabulated, lines visible on our plates at 80 volts but absent at 40 are observed by Dunoyer's method as relatively strong.

In only one instance does Sommer classify in a multiplet a line which we classify in the high-voltage spectrum. This may, perhaps, be ascribed to a coincidence of a relatively faint multiplet line and a strong high-voltage line.

As in the case of rubidium, there is here no definite evidence of stages in the excitation of the rare gas-type spectrum. The lines which appear at the lowest voltage are the strongest lines of this spectrum, though there does seem to be an interval of two volts between the appearance of five of these lines and the others.

Apart from minor inconsistencies, the intensities of spark spectra observed by Sommer resemble the intensities found by the author at 80 volts. Those given by Dunoyer differ in that the higher-voltage lines are much stronger. The relative intensity of spark as compared with arc lines is much less even at 80 volts than with either of the other methods of excitation. Our plates showed the ninth doublet of the principal series, while Sommer only records the third.

\section{POTASSIUM}

Electrical measurements in potassium vapor ${ }^{14}$ gave critical potentials at $19 . \pm 1$ and $23 . \pm 1$ volts. Ionization measurements gave in one or two instances evidence of an increase in ionization at the higher critical potential. The ionization curves resembled the rubidium curve III of Figure 5, and the shape of these curves suggests that the ion current has nearly reached saturation below the critical potential concerned, and, if this is so, a large increase in production of ions would give only a small increase in the measured current. For this reason ionization measurements were repeated under conditions of low-vapor pressure and with both large and small fields to draw the ions to the receiving electrodes. Tube 3 was used and $-V_{1}$ varied from a few volts to 100 volts. With the higher fields curves of the type shown in Figure 6 were obtained. This is the mean of four similar curves, and it indicates an increase in ionization at 19 volts. With small fields no increase is erident at this potential, and the curve is always concare to the voltage axis.

A spectroscopic study of stages in the excitation of the potassium spectrum has been published. ${ }^{15}$ The tube used resembled tube $4 \mathrm{a}$ in principle, and the currents used were rather large. Some spark

"Soft X Rays from Ares in Gases; Mohler and Foote; B. S. Sci. Paper No. 425.

1s Foote, Meggers, and Mohler, Astro. Phys. J., 55, pp. 145-156; 1922. 
lines were visible at 16 volts and strong at 19 volts applied potential. The experiments were repeated, using tubes $4 \mathrm{a}$ and $6 \mathrm{a}$, with the following results: Spectra from tube $6 \mathrm{a}$ with high-vapor pressure and currents of about 0.02 ampere from a cathode area of about $200 \mathrm{~cm}^{2}$ are very similar to those obtained with currents of 0.02 ampere from a cathode of $2 \mathrm{~cm}^{2}$ area in rare vapor. Under either conditions two of the strongest lines are barely visible at 27 volts, many lines appear at 29 and are strongly enhanced at 31 volts. With tube 4a some spark lines appeared with 21 volts and 0.12 ampere, but in another exposure at 23 volts and about the same

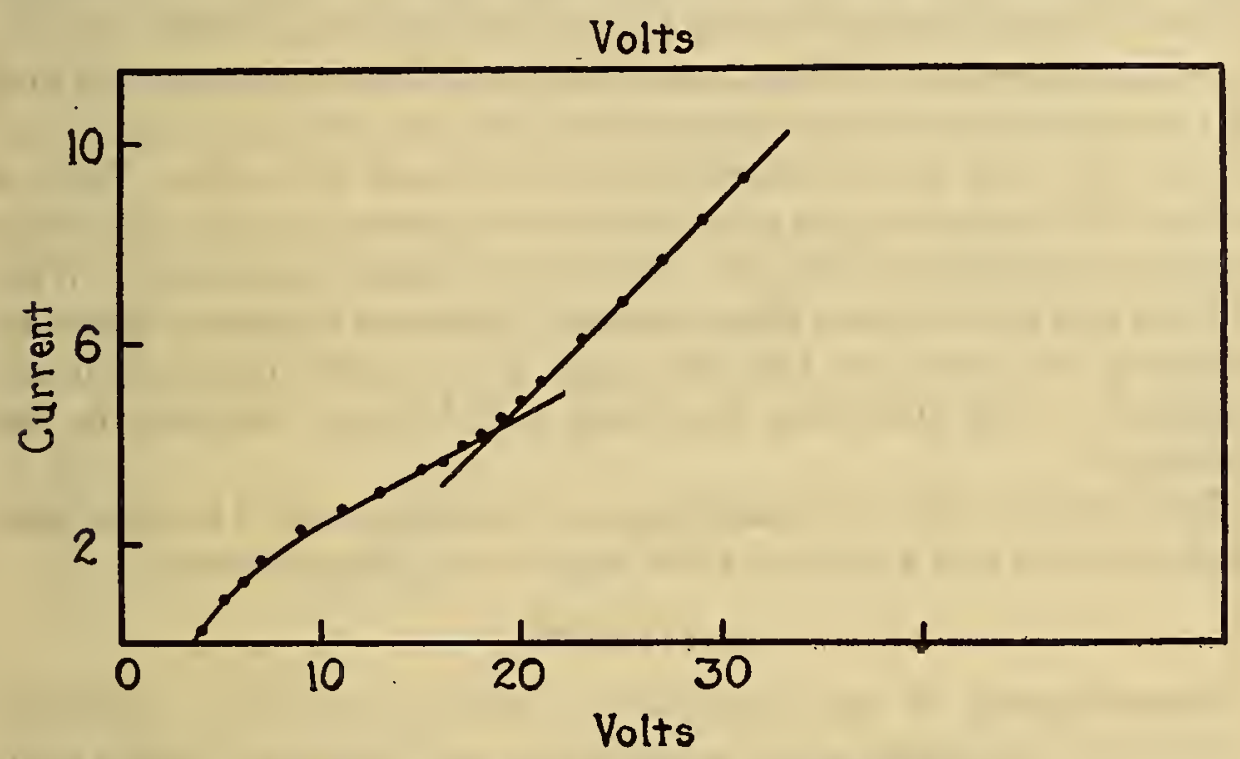

Fig. 6.-Positive ion current in potassium vapor

current they were much fainter. At 20 volts and 0.3 ampere the spark lines are about as strong as at 29 volts with low current. We conclude that the excitation potentials are roughly 19 volts and 28 volts for large and small currents, respectively. The minimum current for multiple excitation is roughly 0.03 ampere per square centimeter.

Nissen ${ }^{16}$ has published a paper on the classification of the potassium spark lines giving series terms which have, as we should expect, numerators equal to four times the Rydberg number. The value of this classification is, however, open to question since no accurate measurements of wave lengths were then available. A recent note by Dahmen ${ }^{17}$ gives precision measurements of 125 spark lines in the range 7100 to $3400 \mathrm{~A}$. The source used was a spark discharge in argon and potassium, and the spectra show a few strong lines and many faint ones not observed by Foote, Meggers, and Mohler (loc. cit.). 


\section{SODIUM}

Published electrical measurements with sodium vapor, ${ }^{18}$ with a tube of type 1 , give a radiation potential at $35 \pm 1.5$ volts. Under some conditions there was an increase in ionization near this voltage. Another radiation potential near 17 volts was of questionable origin since two likely impurities, hydrogen and nitrogen, might give rise to this.

A study of excitation of spark lines ${ }^{19}$ with a tube of type 4 a showed a trace of spark lines at an applied potential of 30 volts. Results of recent experiments with tube $4 \mathrm{a}$ are as follows: With sodium heated to $260^{\circ} \mathrm{C}$. and currents of 0.02 ampere the spark lines were entirely absent at 40 volts. Three of the lines were barely visible at 42 and 43 volts, while many lines appeared at 45 and were much enhanced at 55 volts and in less degree between 55 and 97 volts. With a current of 0.2 ampere the spark lines were present at 39 volts in an intensity comparable with the 45-volt low-current exposure. With 35 volts and 0.35 ampere the lines again appeared in similar intensity except at one point on the slit image where spark lines were much enhanced. This place was the image of a brilliant streamer in the discharge.

We conclude that the spark lines are excited near 44 volts with small currents and about 10 volts lower with large currents.

\section{LITHIUM}

Measurements of the photo-electric effect of radiation produced by electron bombardment of solid lithium and of lithium oxide have been published by McLennan and Clark, ${ }^{20}$ and by Holtsmark, ${ }^{21}$ respectively. Both give potentials ascribed to the excitation of the lithium $K$ spectrum, but the results are not very conclusive and are not in mutual agreement. We believe that greater weight should be given to the result of Holtsmark, who gives the critical potential as 52.5 volts.

We have attempted to measure radiation from lithium vapor in tube 2. Particular pains were taken to secure good insulation between electrodes, but serious difficulties were encountered. Three sets of readings seemed to show a definite increase in radiation between 50 and 60 volts, and the average of these readings is plotted in Figure 7, upper curve. The scale is too small to show up well, and in the lower curve we have plotted on a larger scale the interval between the observed curve and a straight line also included in the figure. It is seen that there is at 54 volts an increase that is very sharp and large compared with accidental irregularities. Though the manner of

18 Mohler and Foote; B. S. Sci. Papers No. 425.

${ }^{10}$ Foote, Meggers, and Mohler; Astrophys. J., 55, pp. 145-156; 1922.

20 "Soft characteristic X rays," Proc. Roy. Soc., 102 A, pp. 389-410; 1923.

21 "Characteristic $X$ rays of light elements," Phys. Zeits, 24, pp. 225-230; 1923. 
selecting the data is open to criticism, Holtsmark's result and spectroscopic evidence bear out the conclusion that there is a critical potential near this voltage.

Results of a search for a spark spectrum of lithium have been published by the author. ${ }^{22}$ Tube 5a was used with rather large currents concentrated by a magnetic field. No precautions were taken against error from oscillations. One line at $2934.15 \pm .1 \mathrm{~A}$ was excited under the following conditions. It was faintly visible on one long exposure at 45 volts, but absent on other plates at 50 . At 55 volts it was still very faint, but at 60 volts it was relatively strong. It was enhanced noticeably between 60 and 100 volts and in a less

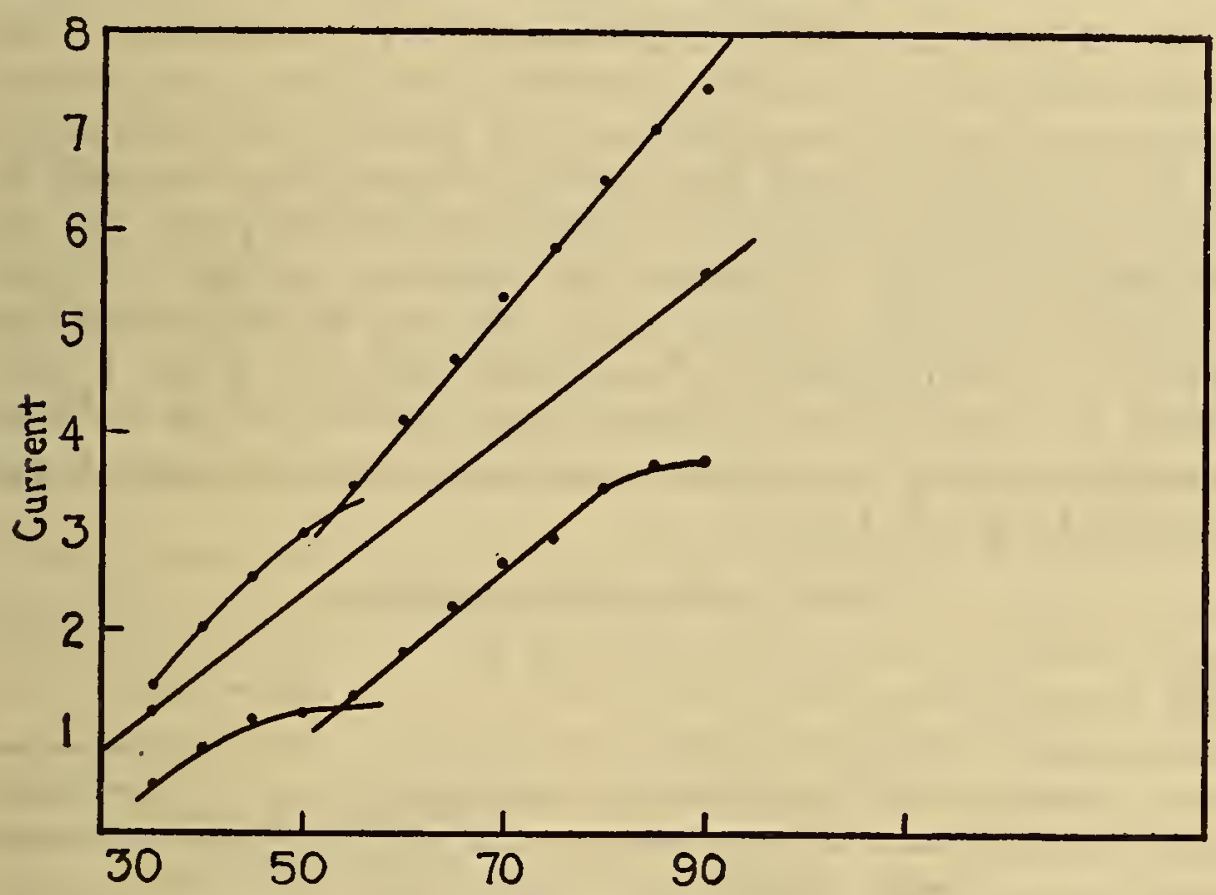

FIG. 7.-Photo-electric effect of the lithium discharge

The upper curve gives observed currents per unit cathode current, the lower curve gives on a larger scale the vertical distances between the upper curve and the straight line below it

degree between 100 and 200 volts. The plates showed the principal series to the tenth line, and the density of 2934 at 100 volts was intermediate between that of the fifth and sixth lines of this series. Because of its excitation potential the line was ascribed to the helium type spark spectrum of lithium. Since this work was published several important papers on this spectrum have appeared.

Morand ${ }^{23}$ has studied the spectrum emitted by high-speed lithium positive rays when they strike a solid target. He found, in addition to the arc spectrum, the line at $2934 \mathrm{~A}$ and several other lines ascribed to $\mathrm{Li}^{+}$, one line of $\mathrm{Li}^{++}$at $4501 \mathrm{~A} \nu=9 N\left(\frac{12}{4}-\frac{12}{5}\right)$, and a new arc series spectrum resembling the ordinary lithium arc spectrum, 
but displaced toward the violet. The line 2934 he found to be double with wave lengths 2933.85 and $2934.5 \mathrm{~A}$. This seemed to support a prediction by the author that the line might correspond to the helium doublet $2 s-2 p_{1,2}$. Unpublished results of Schüler indicate that this classification is wrong. Schüler has published a brief note on the spark spectrum of lithium ${ }^{24}$ excited by a disruptive discharge in which many lines are roughly measured and classified in series of helium arc type with terms of numerator $4 N$. His research is being continued with a large grating spectrograph, and important results will soon be published.

\section{SUMMARY OF RESULTS}

Table 3 gives a correlation of the results with all the alkalies. The measurements of rubidium potentials are probably the most accurate. Estimates of critical potentials based on spectroscopic observations are always more uncertain than purely electrical measurements, for there is no definite criterion for locating the critical point. It was particularly difficult to estimate the minimum voltage for spark excitation with large currents, but in all cases this stage was near point (1). The increase in photo-electric effect at point (1) with sodium and lithium was relatively faint, and the single radiation potentials observed may measure superposed effects of points (1) and (2) instead of point (1) alone.

TABLE 3.-Observed critical potentials

\begin{tabular}{|c|c|c|c|c|c|c|}
\hline $\begin{array}{l}\text { Refer- } \\
\text { ence } \\
\text { No. }\end{array}$ & $\mathrm{Li}$ & $\mathrm{Na}$ & $\mathrm{K}$ & Rb ${ }^{1}$ & Cs & Observed effects \\
\hline & $54 \pm 2$ & $35 \pm 2$ & $19 \pm 1$ & $16.0 \pm .5$ & $14 \pm 2$ & \multirow{3}{*}{$\begin{array}{l}\text { Radiation; increase in ionization; spark } \\
\text { lines with large currents. } \\
\text { Increased radiation; spark lines enhanced } \\
\text { with large currents. } \\
\text { Spark lines with low current. }\end{array}$} \\
\hline $2 \ldots \ldots$ & & $\cdots$ & $23 \pm 1$ & $21.6 \pm .5$ & 1 & \\
\hline 3. & & $44 \pm 2$ & $28 \pm 1$ & 25. $2 \pm 1$ & $21.5 \pm 1$ & \\
\hline
\end{tabular}

1 There is evidence of other radiation potentials of $R b$ at 18 and 68 volts.

\section{INTERPRETATION OF RESULTS}

An alkali atom contains a single valence electron revolving around a core with an electron configuration which is similar to the immediately preceeding rare gas. The Bohr scheme for the distribution of electrons in these atoms is given in Table. 4. The most loosely bound electron group in the rare gas core contains, with the exception of lithium, eight electrons in two subgroups of azimuth numbers 2 and 1. These subgroups probably differ greatly in energy level, the ionization potential of the $n_{1}$ electrons being two or three times that of the $n_{2}$ subgroup..$^{25}$ The $n_{2}$ level is presumably complex, the separations being too small to measure electrically.

24 Naturwiss., 28, p. 579; 1924.

${ }_{25}$ See Interpretation of Critical Potentials, Mohler; Bull., N. R. C., 9, p. 98; 1924. 
potentials of the $n_{2}$ shell of each alkali atom and of the preceding rare gas ion are approximately equal. The latter potentials are known except for neon, and the comparison is shown in Table 5. The

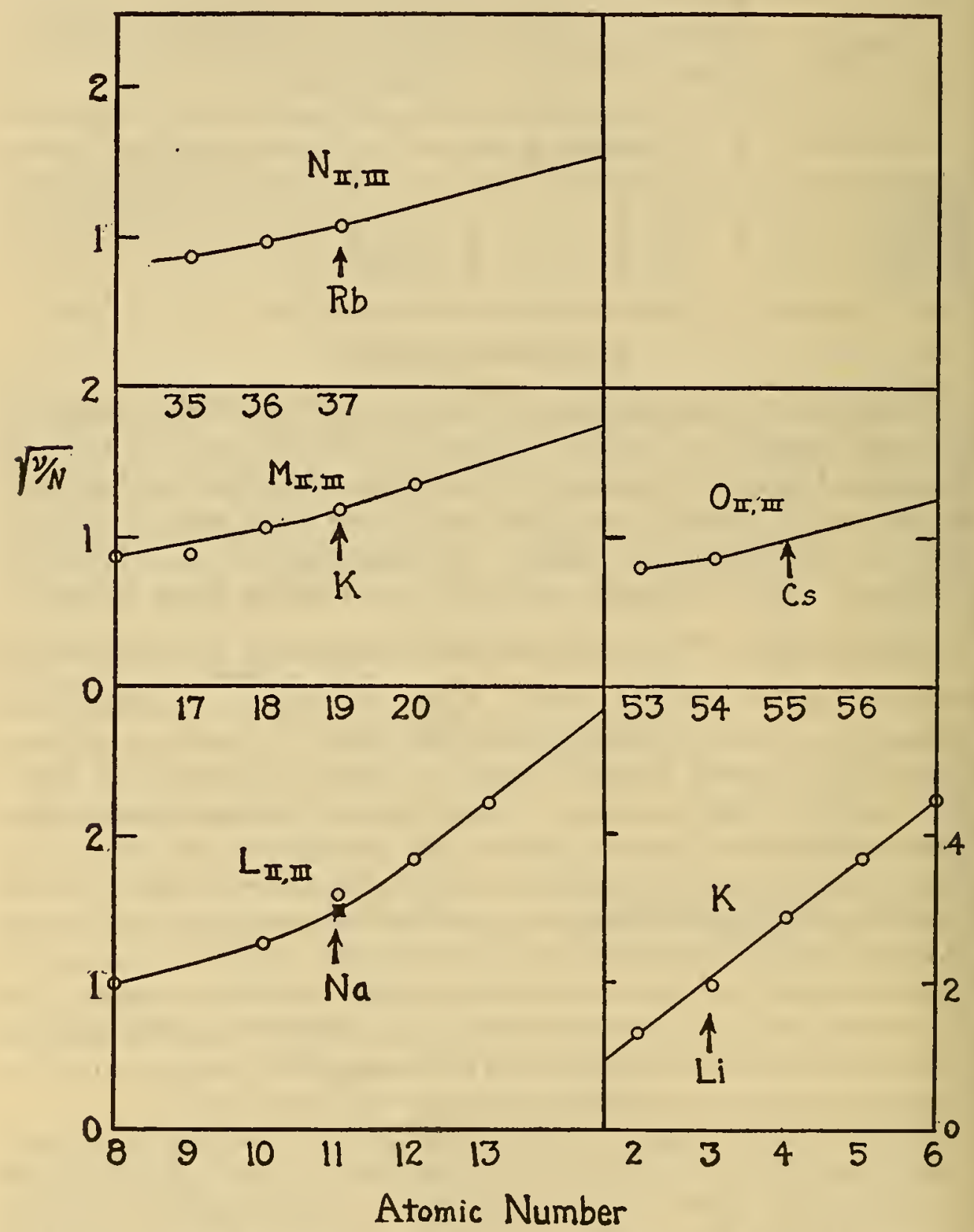

FIG. 8.-Mosely diagrams of energy levels for elements near each of the alkalies

agreement is entirely within the range of observational errors. An exact agreement would not be expected on the basis of the qualitative reasoning given above but it is at least an interesting empirical relation. 
TABLE 5.-Corresponding levels of rare gas ion and alkali atom ${ }^{\mathrm{I}}$

\begin{tabular}{|c|c|c|}
\hline Quantum No. & Rare gas ion & Alkali atom \\
\hline 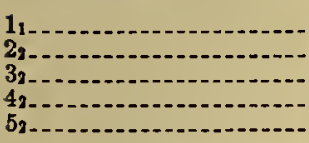 & $\begin{array}{l}\mathrm{He}^{+} 54.2 \\
\mathrm{Ne}^{+} \\
\mathrm{A}^{+} 19.0 \pm .5 \\
\mathrm{Kr}^{+} 15.5 \pm .5 \\
\mathrm{Xe}+13.0 \pm .5\end{array}$ & $\begin{array}{l}\text { Li } 54 \pm 2 \\
\text { Na } 35 \pm 2(31.5) \\
\text { K19.0 } \\
\text { Rb } 16.0 \pm 1 \\
\text { Cs }(13.5)\end{array}$ \\
\hline
\end{tabular}

1 Values in parentheses not observed. Rare gas values are those given by Dejardin (Annales de Phys., 11, pp. $241-327 ; 1924)$, except for $\mathrm{He}^{+}$, where we give the accurately known spectrum limit.

We have given, in detail, reasons for identifying points (1) of Table 3 with an ionization potential of the normal atom, since it might be predicted that there would be a series of lower excitation potentials. The lowest excitation stage would involve removal of an electron from the rare gas shell to the valence shell. In the case of sodium we would have, in the excited state, two $3_{1}$ electrons moving in the field of a charge 11 screened by 9 electrons. The work required to ionize this excited atom would be about the same as the first ionization potential of magnesium where there is a charge of 12 screened by 10 electrons. It follows that the hypothetical excitation potential of sodium will be 7 or 8 volts less than the $L_{\text {II, III }}$ limit, and for the heavier alkalies it will be 5 or 6 volts less than the corresponding $n_{2}$ level. No such potential is observed, and we conclude that displacement of an electron from a completed shell to a valence shell is relatively improbable if not impossible. The most probable type of excitation is, as in the case of high frequency $\mathrm{X}$ rays, complete removal of an electron from the atom.

The radiation measured photo-electrically probably results from a true X-ray radiation process in which the valence electron falls into the rare gas shell. The energy of the atom in the initial state is given by the observed potential (point (1), Table 3) and that of the final state by the first ionization potential of the alkali. The quantum radiated is given by the difference of these two potentials. (No approximation is introduced.) Table 6 gives computed potentials and wave lengths for the X-ray emission line (presumably a doublet) and for the hypothetical excitation without ionization. It emphasizes the fact that an X-ray emission line does not measure an excitation potential and can not be a "resonance line" of a normal atom. It is probably identical with the "single line spectrum" of the ion.

TABLE 6

\begin{tabular}{|c|c|c|c|c|c|}
\hline Element & $\begin{array}{l}\text { X-ray } \\
\text { limit }\end{array}$ & Unobserved & zcitation & X-ray emi & ion line \\
\hline $\begin{array}{l}\mathrm{Li} \\
\mathrm{Na} \\
\mathrm{K} \\
\mathbf{R} \mathrm{b} \\
\mathrm{Cs}\end{array}$ & $\begin{array}{c}\text { Volts } \\
54 \\
(31.5) \\
19 \\
16 . \\
(13.5)\end{array}$ & $\begin{array}{c}\text { Volts } \\
144 \\
(23.9) \\
12.9 \\
10.3 \\
(8.3)\end{array}$ & $\begin{array}{r}\lambda(A) \\
280 \\
516 \\
958 \\
1,200 \\
1,490\end{array}$ & $\begin{array}{c}\text { Volts } \\
248.6 \\
(26.4) \\
14.7 \\
11.8 \\
(9.6)\end{array}$ & $\begin{array}{r}\lambda(A) \\
254 \\
467 \\
840 \\
1,050 \\
1,290\end{array}$ \\
\hline
\end{tabular}

1 Assuming Be are limit roughly 10 volts.

Contrary tu the selection principle for azimuth numbers. 


\section{IONIZATION POTENTIALS OF IONS}

The visible and near ultra-riolet spectra excited near the potentials of Table 3 are shown by their structure to be first order spark spectra of rare gas arc type. Their excitation involves a double processremoval of the valence electron, and removal or displacement of an electron in the rare gas shell. This excitation may be effected in the following ways:

1. By removal of both electrons by a single impact.

2. By removal first of the rare gas shell electron followed by removal of the valence electron by another electron collision before the ion has time to recombine.

3. By successive collisions in the reverse order of 2 .

4. By remoral of one electron and displacement of the other to a higher quantum orbit by single or successive impacts.

5. The excitation may be accomplished by three or more successive impacts.

The first process is distinguished from the second, third, and fifth by the fact that it is the only type of excitation which will occur with low-current density. The probability of the second and third processes will increase as the square of the current, and, hence, the excitation will be favored by high currents. Processes of the fifth type will only occur with excessive currents and can be excluded from consideration.

As to the relative probability of process (4) as compared with the first three there is no safe basis for prediction, though in the case of arc spectra we know that excitation without ionization is more probable than emission resulting from recombination of an ion and electron. It is, however, likely that most of the visible and near ultra-violet lines of the alkali ions have excitation potentials which differ but little (one or two volts) from their ionization potentials. This follows from the similarity between this spectrum and the rare gas arc spectrum, and the experimental evidence that excitation potentials of visible rare gas arc lines are only in a few instances distinguishable from the ionization potentials. In the following we will consider the potentials required to excite spark lines as if they were ionization potentials, for the uncertainty introduced is probably no greater than the experimental errors. The fact that we found no measureable difference in excitation potentials of the different lines is evidence that they all belong to the same spectrum and is consistent with the above considerations.

The critical potential (3), Table 3, measures the work required for process 1, viz, double ionization by a single collision, while excitation of type 2 will occur at the lowest observed potential 1 of Table 3. The critical potential for a double excitation of type 3 can be computed from the known values for types 1 and 2 . 
$V_{1}=$ work required to remove the valence electron from the normal atom (given by the arc limit).

$V_{2}=$ work required to remove a single electron from the rare gas shell of the normal atom (point 1 , Table 3 ).

$V_{3}=$ work of double ionization (point 3 , Table 3 ).

$V_{1}{ }^{\prime}=$ work required to remove the valence electron from the atom ionized from the rare gas shell.

$\nabla_{2}^{\prime}=$ work required to remove one electron from the rare gas shell of the ion with the valence electron removed (spark spectrum limit).

$V_{3}=V_{2}+V_{1}^{\prime}=V_{1}+V_{2}^{\prime}$.

Knowing $V_{3}, V_{2}$, and $V_{1}$ we can find $V_{1}^{\prime}$ and $V_{2}^{\prime}$. The results are given in Table 7. $V_{2}^{\prime}$ gives the limiting frequency of the spark spectrum and is the critical potential for a double excitation of type 3. It seems likely that this type of excitation is more probable than type 2. (Ionization curves indicate that the majority of ions would be ionized from the valence shell.) Point 2, Table 3, may be identified with $V_{2}^{\prime}$, for the potentials fall within the limits of error and in the case of rubidium there was a marked enhancement of spark lines near this voltage.

TABLE 71

\begin{tabular}{|c|c|c|c|c|c|c|}
\hline Element & $v_{1}$ & $v_{2}$ & $v_{\mathbf{z}}$ & $V_{\mathbf{l}^{\prime}}$ & $v_{2}^{\prime}$ & $\begin{array}{l}\text { Point (2), } \\
\text { Table 3, }\end{array}$ \\
\hline $\begin{array}{l}\mathrm{Li}- \\
\mathrm{Na}- \\
\mathrm{K}\end{array}$ & $\begin{array}{l}5.4 \\
5.1 \\
4.3 \\
4.2 \\
3.9\end{array}$ & $\begin{array}{c}54 . \\
(31.5) \\
19 . \\
16.0 \\
(13.5)\end{array}$ & $\begin{array}{l}(67.5) \\
44 \\
28 \\
25.2 \\
21.5\end{array}$ & $\begin{array}{r}(13.5) \\
(12.5) \\
9 \\
9.2 \\
(8.0)\end{array}$ & $\begin{array}{l}(62.1) \\
38.9 \\
23.7 \\
21.0 \\
17.6\end{array}$ & $\begin{array}{c}233 \\
21.6\end{array}$ \\
\hline
\end{tabular}

1 Values in parentheses are not observed. In the casc of Lithium we have computed $V_{1}^{\prime}$ on the assump. tion that the valence electron moves in a bydrogenic field around a charge of 2.

\section{LITHIUM}

The lithium $K$ electrons have orbits of azimuth number 1 , and though we have included lithium data in comparison with other alkalies where azimuth 2 electrons are involved there is no reason to predict analogous phenomena. We have referred to the discovery by Morand ${ }^{27}$ of a new spectrum resembling the arc spectrum, but with corresponding series terms of slightly higher frequency. He suggests that the spectrum is emitted by an atom previously excited by displacement of a $K$ electron to a metastable orbit and designates this excited atom as ortholithium in analogy with orthohelium. From general approximate relations between arc spectra and spark spectra he estimates the potential required for the excitation as 45 volts. 
This corresponds to $1 \mathrm{~S}-2 \mathrm{~s}$ of helium. (The computation applies, strictly speaking, to $\mathrm{Li}^{+}$with the valence electron removed.) The potential agrees with our estimate of the excitation potential of normal lithium (Table 6) of 44 volts which is based on entirely different reasoning. By similar reasoning he computed the spark limit as 64.7 volts, while we in another manner estimate 62 volts (Table 7 ). Morand gives as evidence for his theory our statement that in one instance a trace of the spark line at $2934 \mathrm{~A}$ appeared with 45 volts applied potential. Unfortunately the evidence is rather unreliable, as no precautions were taken against errors from oscillations in the discharge. While we have reached similar conclusions as to the magnitudes of potentials involved in lithium excitation, both arguments are inconclusive and the experimental verification is still very incomplete.

\section{MiSCELLANEOUS RESULTS}

We give some evidence of critical potentials far above the limit of the first spark spectrum, viz, a 68-volt radiation potential of rubidium and a second spectrum of caesium which is excited somewhere between 40 and 80 volts. Dejardin finds spectra of krypton and xenon with excitation potentials of 59 and 51 volts, respectively, and a correspondence with the high voltage alkali spectra suggests itself. Possibly the excitation is associated with the $n_{1}$ level, but speculation on this point would be premature.

Table 2 shows relative intensities of spectra of caesium excited in the thermionic discharge, in the high voltage disruptive discharge used by Sommer, and in the induction ring discharge as given by Dunoyer. Some qualitative conclusions can be drawn as to the effective voltage and current density in these discharges. The two spark spectra of caesium which have widely different excitation potentials appear in nearly the same relative intensity in the thermionic discharge at 80 volts and in the disruptive discharge. This indicates that the effective voltage of the latter is about 80 volts. Dunoyer obtains the high-voltage lines in much greater intensity, so that the effective voltage abtainable in the ring discharge must be much higher than this. Both find the relative intensity of spark as compared with arc lines much greater than that in the thermionic discharge. In the case of the disruptive discharge this difference can be ascribed to a very much greater instantaneous current density. In the case of the induction discharge we can draw no conclusion, since the voltages are not comparable. Dejardin (loc. cit.) reaches a similar conclusion as concerns the voltage attainable in the induction discharge by comparison with L. and E. Bloch's researches on the rare gases and mercury. 
Considerable theoretical interest attaches to the conditions for the excitation of the potassium arc line, $1 \mathrm{~s}-3 \mathrm{~d}$ at $4642 \mathrm{~A}$, and some recent observations should be mentioned. Foote, Mohler, and Meggers ${ }^{28}$ published a note in which it was shown that the line was excited at low voltage with high currents but not with small currents. In the present work with tube 6 a (see section on experimental results), under conditions of small current density and high but variable vapor pressure, the line was always present, but in quite different intensities on different exposures. The fact that vapor pressure as well as ion concentration may bring out the line is concordant with the observation of Datta ${ }^{29}$ that the line appears in absorption in dense vapor. Unfortunately, our experiments give no quantitative information as to the effect of pressure.

\section{CONCLUSIONS}

It is shown that the first critical potential above the arc limit measures the work required to ionize the atom from the rare gas shell. This energy level is in each instance equal to the corresponding level of the neighboring singly charged rare gas ion. The failure to detect radiation potentials below this ionization potential suggests that the excitation process is of the type involved in X-ray emission.

Double excitation of an alkali atom may be effected by a single electron impact, but with current densities greater than a few hundredths of an ampere per square centimeter excitation by successive collisions also takes place. From the observed minimum potentials for these two types of excitation we compute the limiting frequency of the ion spectrum.

Caesium has a second spark spectrum which is excited between - 40 and 80 volts. Apart from this, the observed lines of each enhanced spectrum appeared at the same potential, or at least within a range of about 2 volts.

WASHington, December 19, 1924.

28 "An exception to the principle of selection," Phil. Mag., 43, pp. 659-661; 1922.

29 Proc. Roy. Soc. 101, pp. 539-547; 1922. 


